\section{Synthesis of PEDOT/ZnO Photocatalyst: Validation of Photocatalytic Activity by Degradation of Azo RR45 Dye Under Solar and UV-A Irradiation*}

\author{
Z. Katančić, ** S. Šuka, K. Vrbat, A. Tašić, and Z. Hrnjak-Murgić \\ University of Zagreb, Faculty of Chemical Engineering and Technology, \\ Marulićev trg 19, Zagreb, Croatia
}

doi: 10.15255/CABEQ.2017.1124

Original scientific paper Received: March 16, 2017 Accepted: November 3, 2017

To study the photocatalytic efficiency of wastewater treatment processes, the nanocomposites of conducting polymer poly(3,4-ethylenedioxythiophene) (PEDOT) and ZnO nanoparticles were prepared by in-situ synthesis. $\mathrm{ZnO}$ is an excellent photocatalyst under UV light, but due to high band gap, photons of visible light have insufficient energy to excite electrons from valence to conductive band, which limits its activity under visible light and therefore practical usage is limited. The PEDOT conductive polymer was used to increase the photocatalytic activity of $\mathrm{ZnO}$ since conductive polymers are known as efficient electron donor and good electron transporters upon visible-light excitation. Polymerization of pure PEDOT and PEDOT/ZnO nanocomposites was carried out at varying monomer:oxidant ratio $(1: 2 ; 1: 3 ; 1: 5)$ with the ammonium persulfate (APS) used as the oxidant. Samples were characterized by FTIR spectroscopy, XRD analysis, SEM microscopy, UV-Vis spectroscopy and TG analysis. Photocatalytic activity was assessed through removal of C.I. Reactive Red 45 (RR45) azo dye under simulated Solar and UV-A irradiation. Photocatalysis was monitored by measuring discoloration of RR45 using UV/Vis spectroscopy. The results indicate that very low concentration of PEDOT conductive polymer in PEDOT/ZnO nanocomposite can significantly contribute to the efficiency of the photocatalytic process during wastewater treatment.

Keywords:

azo dye, conductive polymers, photocatalysis, poly(3,4-ethylenedioxythiophene), simulated solar irradiation, zinc oxide

\section{Introduction}

Organic synthetic dyes today represent one of the inevitable additives appearing in many areas of human life, from food, clothing, cosmetics, pharmaceuticals and personal care products, and plastic items that are used on a daily basis ${ }^{1}$. When released in the environment, they can cause negative effects to aquatic organisms and they present serious threat to humans ${ }^{2}$ as well. Thus, in order to avoid the negative environmental impact by discharge of such wastewaters, an efficient treatment is required. Azo dyes are considered non-degradable, and common degradation processes such as physicochemical treatment, oxidative techniques and other are not able to completely remove dyes from the contaminated wastewaters ${ }^{3}$. Heterogeneous photocatalytic oxidation process is promising for removal of syn-

\footnotetext{
*Presented at the " $4^{\text {th }}$ International Symposium on Environmental Management - Towards Circular Economy (SEM2016), December 7 - 9, Zagreb, Croatia"

${ }^{* *}$ Corresponding author. Tel: +385 14597 118; Fax: +385 14597142 E-mail address: katancic@fkit.hr, University of Zagreb, Faculty of Chemical Engineering and Technology, P.O. Box 177, HR-10000, Zagreb, Croatia
}

thetic dyes during wastewater treatment ${ }^{4-6}$. Heterogeneous photocatalysis includes a large variety of reactions: mild or total oxidations, dehydrogenation, hydrogen transfer, metal deposition, water detoxification, gaseous pollutant removal, etc. The most common heterogeneous photocatalysts are transition metal oxides, which are semiconductors and can produce an electron and hole by photoactivation. Due to the generation of holes and electrons, oxidation-reduction reactions take place at the surface of semiconductors during the photocatalysis. The most promising metal oxides photocatalysts are titanium oxide $\left(\mathrm{TiO}_{2}\right)$ and zinc oxide $(\mathrm{ZnO})$ that are used for the photocatalytic decomposition of organic dyes under ultraviolet (UV) light irradiation $(<380 \mathrm{~nm}) . \mathrm{ZnO}$ is chemically stable, non-toxic, a low-cost alternative to $\mathrm{TiO}_{2}{ }^{7}$ and in some cases even more efficient than $\mathrm{TiO}_{2}{ }^{8}$. However, the low solar energy conversion efficiency limits its higher practical applications. Efforts have been made to extend the light absorption of $\mathrm{ZnO}$ into the visible region and increase its photocatalytic activity using methods such as metal ${ }^{9-11}$ and non-metal doping ${ }^{12-15}$, noble metal deposition ${ }^{16,17}$ and forming composites with narrow semiconductors. The nanohybrid/con- 
ducting polymer composites have also been studied and have been of great interest over the past decade $^{18}$. Many conductive polymers are efficient electron donors and good electron transporters upon visible-light excitation ${ }^{19,20}$ and allow high mobility of charge carriers ${ }^{21,22}$. Thus, they can improve the electronic conductivity and photocatalytic activities of metal oxide. Muktha et al. ${ }^{23}$ investigated photocatalytic activity of poly(3-hexylthiophene)/ $/ \mathrm{TiO}_{2}$ composites and it was established that nanocomposites obtained better performance than the single components. Goubard et al..$^{24}$ described the production of nanohybrid materials by photopolymerization of 3,4-ethylenedioxythiophene on $\mathrm{TiO}_{2}$. Because of that, PEDOT conductive polymer (structural formula shown in Fig. 1) seems a good choice to study photocatalytic activity of PEDOT/ $\mathrm{ZnO}$ nanocomposites. The properties of neutral PEDOT polymer are low electronic bandgap of 1.6$1.7 \mathrm{eV}$, defined as the onset of the $\pi-\pi^{*}$ absorption demonstrated at $\lambda_{\text {max }}$ of $610 \mathrm{~nm}$. In general, the electronic bandgap of a conjugated polymer chain can be controlled by changing the degree of $\pi$-overlap along the backbone via steric interactions, and by controlling the electronic character of the conjugated $\pi$-system with electron-donating or accepting substituents ${ }^{25}$. The variability of PEDOT conductivity can be obtained through the choice of suitable counter-ion dopants. Reynolds and $\mathrm{Kumar}^{26}$ reported that by increasing the ratio of oxidant $\left(\mathrm{FeCl}_{3}\right)$ to monomer above two during the chemical polymerization of EDOT, a fraction of polymerized PEDOT becomes insoluble in organic solution as the result of crosslinking. If the oxidant $\left(\mathrm{FeCl}_{3}\right)$ to monomer ratio is above five, a completely insoluble polymer is obtained. Because of the low oxidation potential and relatively low bandgap, PEDOT has exhibited excellent electrochemical and spectroscopic properties not found in other polymers.

In the present study, conductive polymer nanocomposites were prepared by in situ oxidative polymerization of EDOT monomer in the presence of $\mathrm{ZnO}$ nanoparticles and PEDOT was deposited on the surface of $\mathrm{ZnO}$ (denoted PEDOT/ZnO). The morphology, structure, optical and thermal properties of PEDOT/ZnO nanocomposite photocatalysts were investigated. The photocatalytic activity of $\mathrm{PEDOT} / \mathrm{ZnO}$ nanocomposites was examined in the photocatalytic degradation of Reactive Red 45 azo dye under UV-A and simulated solar irradiation to determine an optimum EDOT:oxidant (ammonium persulfate, APS) molar ratio for the best performance. After studying the structure-activity relationship, it is deduced that the good performance of $\mathrm{PEDOT} / \mathrm{ZnO}$ is achieved due to the conjugated structure and good conductivity of the polymer, as well as due to PEDOT - $\mathrm{ZnO}$ interactions.

\section{Experimental}

\section{Materials}

For synthesis, 3,4-ethylenedioxythiophene (EDOT), $99 \%$ (Acros Organics), Ammonium persulfate $\left(\mathrm{NH}_{4}\right)_{2} \mathrm{~S}_{2} \mathrm{O}_{8}$, (Kemika), Zinc oxide nanoparticles (ZnO), (Sigma-Aldrich) BET 15-25 $\mathrm{m}^{2} \mathrm{~g}^{-1}$, and hydrochloric acid (HCl) $37 \%$ (Carlo Erba Reagents) were used. Commercial organic dye C.I. Reactive Red 45 dye (RR45) Ciba-Geigy, Basel, was used without purification.

\section{Synthesis of photocatalyst}

The synthesis of PEDOT/ZnO nanocomposite photocatalysts were carried out by chemical oxidative polymerization using ammonium persulfate $\left(\mathrm{NH}_{4}\right)_{2} \mathrm{~S}_{2} \mathrm{O}_{8}$ (APS) as oxidant. PEDOT conductive polymer was in-situ synthesized in the presence of $\mathrm{ZnO}$ nanoparticles, while the ratio of monomer:oxidant (EDOT:APS = 1:2, 1:3, 1:5) was varied to obtain three different photocatalysts. The molar ratio EDOT:ZnO was 0.36 for all studied PEDOT/ZnO samples. Sample PEDOT/ZnO (1-2) was prepared as follows. EDOT monomer $(0.009 \mathrm{~mol})$ and $\mathrm{ZnO}$ $(0.025 \mathrm{~mol})$ were dispersed in $150 \mathrm{~mL}$ water and stirred for 30 mins. After that, $100 \mathrm{~mL}$ of APS solution $(0.018 \mathrm{~mol})$ was added and polymerization reaction was carried out for another $24 \mathrm{~h}$ at room temperature under nitrogen atmosphere. The synthesized $\mathrm{PEDOT} / \mathrm{ZnO}$ nanocomposite precipitate was obtained by centrifugation and washed for several times with water and ethanol to remove the redundant oxidant. The sample was finally dried at $60^{\circ} \mathrm{C}$ under vacuum for $24 \mathrm{~h}$. The same procedure was used to prepare the other two nanocomposite photocatalysts, where 0.027 and $0.045 \mathrm{~mol}$ was the concentration of APS oxidant (PEDOT/ZnO 1-3, 1-5). The pure PEDOT polymers without $\mathrm{ZnO}$ were prepared under the same conditions of synthesis.

\section{Characterization of photocatalysts}

The PEDOT and PEDOT/ZnO nanocomposite photocatalysts were characterized by FTIR spectroscopy by Perkin Elmer Spectrum One spectrophotometer with ATR chamber. Samples were used in their basic powder form, without prior preparation. Spectra were recorded in the wavenumber range $4000 \mathrm{~cm}^{-1}$ to $650 \mathrm{~cm}^{-1}$. The thermal stability of studied samples was followed by TGA analyzer TA Instruments Q500. The weight of samples was cca. $10 \mathrm{mg}$, heating rate was $10^{\circ} \mathrm{C} \mathrm{min}^{-1}$ in an air atmosphere in temperature range from $25^{\circ} \mathrm{C}$ to $600{ }^{\circ} \mathrm{C}$. The crystal structure of synthesized nanocomposite photocatalysts was characterized by X-ray diffraction analysis (XRD), Shimadzu XRD-600 instrument. 
Measurement was performed under the conditions: $2 \Theta$ angle from $5^{\circ}$ to $70^{\circ}$, step $0.02^{\circ}, 0.6 \mathrm{~s} / \mathrm{step}$. Morphology of the studied samples was examined by scanning electron microscopy (SEM), Tescan Vega 3 instrument. Prior to measurement, the surface was sputter coated with $\mathrm{Au} / \mathrm{Pt}$ layer. UV/Vis diffuse reflectance spectra of the studied powder $\mathrm{PEDOT} / \mathrm{ZnO}$ composite photocatalysts were made over the range $200 \mathrm{~nm}$ to $700 \mathrm{~nm}$ at a spectral resolution of $\sim 0.3-10 \mathrm{~nm}$ using Ocean Optics USB $2000+$ spectrophotometer equipped with the integrating sphere.

\section{Photocatalytic activity}

The photocatalytic activity of synthesized nanocomposite photocatalysts was determined by monitoring discoloration of wastewater polluted with Reactive Red 45 (RR45) dye. Initial concentration of dye was $30 \mathrm{mg} \mathrm{L}^{-1}$ with the photocatalysts concentration of $1 \mathrm{~g} \mathrm{~L}^{-1}$. The photocatalysis was performed in $100 \mathrm{~mL}$ batch reactor at room temperature. As the irradiation source, UV-A lamp Pen Ray UVP (254 nm) and solar irradiation simulator Oriel Newport (Osram XBO 450 W lamp) were used. Before performing photocatalysis, the adsorption equilibrium was reached by stirring the samples 30 minutes in the dark, and the photocatalysis process was carried out for another 90 minutes. To monitor the process of photocatalytic degradation of RR45 dye, the absorbance at $\lambda_{\max }=542 \mathrm{~nm}$ was measured by UV/Vis spectrophotometer Perkin Elmer Lambda EZ 201. Samples were taken from the reactor every 15 minutes and filtered using Chromafil XTRA RC ( $25 \mathrm{~mm}, 0.45$ microns) filters. The results are presented as the ratio of remaining and initial concentration of dye in wastewater. Concentration at the specific time of measurement was calculated according to equation:

$$
\text { Concentration }(t)=A(t) / A_{0}
$$

where $A_{0}$ and $A(t)$ were the initial absorbance and the absorbance of RR45 at the time of measurement.

\section{Results and discussion}

\section{FTIR analysis}

The samples of PEDOT conductive polymers and PEDOT/ZnO nanocomposite photocatalysts were recorded by FTIR spectroscopy. In Fig. 1, the spectra of three pure PEDOT conductive polymers are given that differ in structure because of the variation of APS oxidant amount during the synthesis. The main vibrations bands, according to their chemical structure, appear in the region $1700 \mathrm{~cm}^{-1}$ to 600 $\mathrm{cm}^{-1}$ of the spectra as may be seen. In Fig. 1, vibra- tion bands at 1482,1440 and $1363 \mathrm{~cm}^{-1}$ originate from the stretching of $\mathrm{C}=\mathrm{C}$ and $\mathrm{C}-\mathrm{C}$ in the thiophene ring. The $\mathrm{C}-\mathrm{S}$ bond vibrations in the thiophene ring may be seen at 980,845 and $685 \mathrm{~cm}^{-1}$. Then, bands at $1150,1093,1040 \mathrm{~cm}^{-1}$ are assigned to stretching in the alkylenedioxy group $(-\mathrm{COROC}-)^{27-30}$. According to the literature ${ }^{31}$ characteristic vibration bands at FTIR spectra of PEDOT conducting polymer can be found on the different position due to $\mathrm{p}$-doping, $\mathrm{n}$-doping and neutral polymer. The development of charged doped structure of PEDOT during the oxidation process is recognized by the following bands: 1513, 1319, $1195,1090,1060,980$ and $845 \mathrm{~cm}^{-1}$. The same vibration bands are absent in FTIR spectra of the neutral polymer. Further, the vibration bands that are below $1200 \mathrm{~cm}^{-1}$ are similar for both types of $\mathrm{p}$ - and the n-doped charged forms, and they differ only in the relative intensities. On the other hand, the difference in the $\mathrm{p}$ - and $\mathrm{n}$-doped forms may be seen from the vibration bands above $1200 \mathrm{~cm}^{-1}$. The p-doped form of PEDOT shows the bands at 1513 and at $1315 \mathrm{~cm}^{-1}$, while in the n-doped form the bands are at 1285 and $1237 \mathrm{~cm}^{-1}$. Thus, PEDOT (1-5) sample does not show vibration bands for p-doped charged form, but indicates n-doped polymer (significantly broader bands from 1200 to 1290 $\mathrm{cm}^{-1}$ ). The other two samples PEDOT (1-2) and (1-3) (with lower concentration of APS) show opposite appearance of vibration bands that are characteristic for $\mathrm{p}$-doped polymer charged form (bands at 1513 and $1315 \mathrm{~cm}^{-1}$ ). In Fig. 2, the spectra of three PEDOT/ZnO nanocomposite photocatalysts are presented. Only vibration bands of PEDOT polymer are observed because $\mathrm{ZnO}$ bands are seen at lower region ${ }^{32}$, below $650 \mathrm{~cm}^{-1}$. It is interesting to observe that vibration bands of PEDOT in nanocomposite, synthesised under the same conditions as the pure polymer, show variation in charged forms. All three samples show only n-doped charged form, which is seen by the appearance of two bands at 1285 and $1237 \mathrm{~cm}^{-1}$. In FTIR spectra, only slight variation in the region $730-690 \mathrm{~cm}^{-1}$ is observed, indicating higher concentration of $\mathrm{C}-\mathrm{S}$ bonds, and higher intensity of vibration at $988 \mathrm{~cm}^{-1}$ show increased doping of PEDOT/ZnO (1-2) sample. Higher intensity of bands vibration at 1150-1130 $\mathrm{cm}^{-1}$ and at $1090-1040 \mathrm{~cm}^{-1}$ is due to increased concentration of the $-\mathrm{C}-\mathrm{O}$ bonds, indicating higher concentration of polymer in PEDOT/ZnO samples (1-3 and 1-5) that can also originate from branches or crosslinks. The appearance of band vibrations in the region at 1600 to $1680 \mathrm{~cm}^{-1}$ indicates the existence of carbonyl groups, which is related to the side reactions such as overoxidation that can cause decrement of conductivity due to nonconductive side-chains on the conductive PEDOT backbone. 


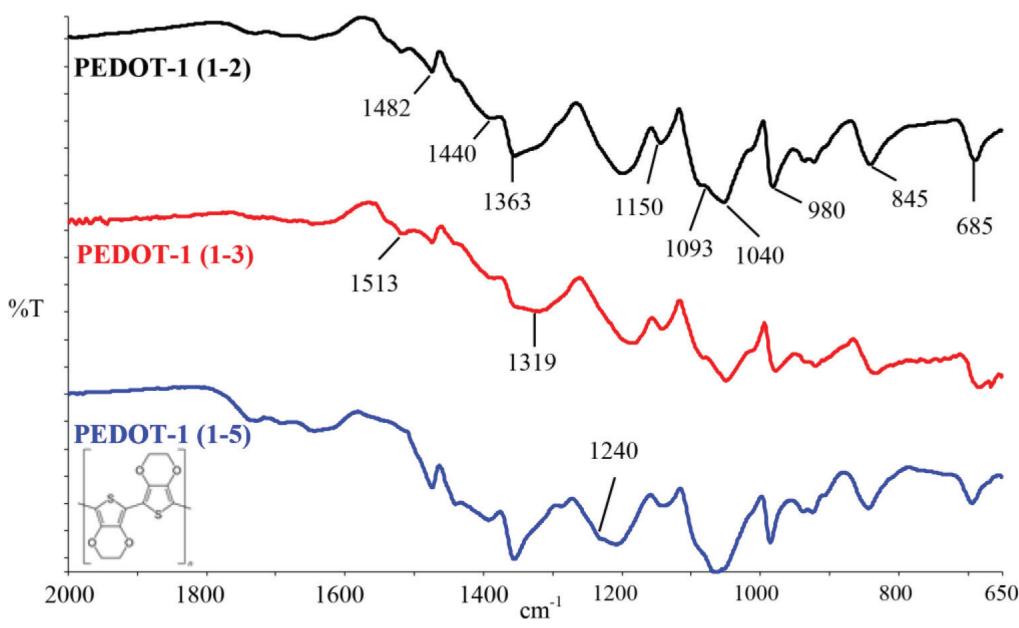

Fig. 1 - FTIR spectrograms of PEDOT samples synthesized by various monomer to APS oxidant ratio $(1: 2,1: 3,1: 5)$

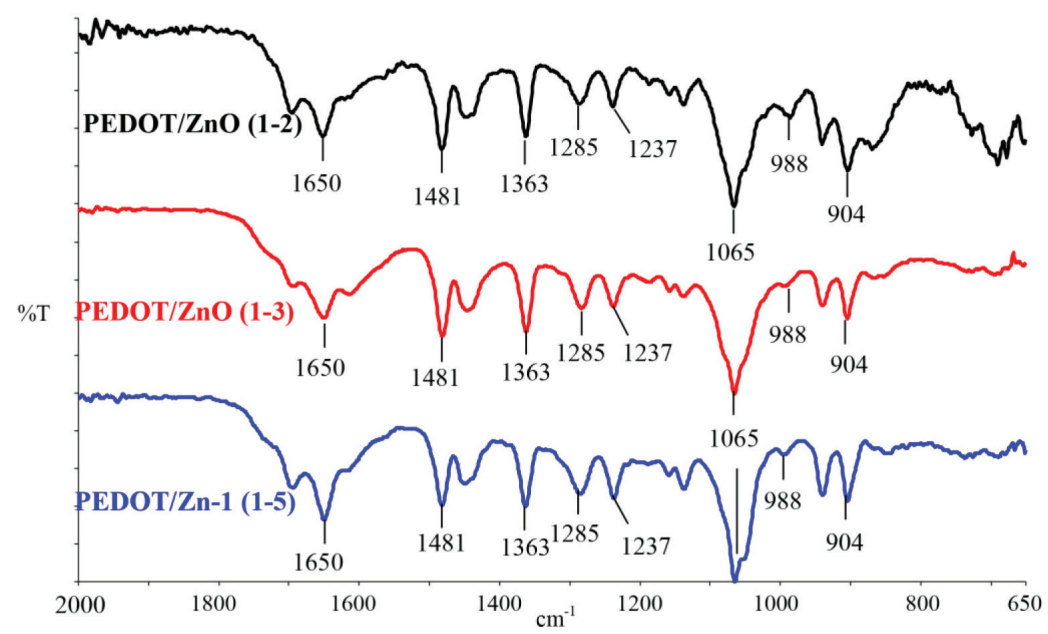

Fig. 2 - FTIR spectrograms of PEDOT/ZnO samples synthesized by various monomer to APS oxidant ratio $(1: 2,1: 3,1: 5)$

\section{TG analysis}

TG and dTG curves of the studied samples are presented in Figs. 3 and 4 and describe confirmed variations in PEDOT chemical structures, which are seen as variation of their thermal stability. In Fig. 3, the results indicated degradation of pure PEDOT conductive polymer in two steps for all three samples. The pure PEDOT samples are rather stable up to the temperature of $250{ }^{\circ} \mathrm{C}$ as the major decomposition occurs in the region between $150{ }^{\circ} \mathrm{C}$ and $350{ }^{\circ} \mathrm{C}(70$ mass $\%)$, and the second smaller step of degradation occurs between $350{ }^{\circ} \mathrm{C}$ to $520{ }^{\circ} \mathrm{C}$. The weight loss at temperature of maximum degradation rate $\left(T_{\max 1}\right)$ of cca $305{ }^{\circ} \mathrm{C}$ may be attributed to the degradation of the PEDOT main chains ${ }^{33}$.

However, the results of $T_{\max 2}$ reveal the difference in PEDOT polymer chain structure formed regarding the concentration of APS oxidant. Higher $T_{\max 2}$ temperatures indicate higher thermal stability of that fraction of polymer that can be the result of the presence of polymers of higher molecular weight (longer chains), presence of branch chains or even some crosslinks. ${ }^{34}$ So, the polymer with the lowest concentration of APS oxidant has the lowest $T_{\max 2}=421{ }^{\circ} \mathrm{C}$, which increases for the other two PEDOT samples $\left(T_{\max 2}=472{ }^{\circ} \mathrm{C}\right)$ as the APS concentration increases reflecting the variations in chemical structure. It is assumed that broadening of maximum of $T_{\max 2}$ for PEDOT (1-5) also describes variation and complex structure that is the result of high concentration of APS.

PEDOT/ZnO nanocomposites photocatalysts show different weight loss depending on APS amount (Fig. 4). This clearly indicates various chemical structures and charged forms of polymers formed during in situ synthesis of PEDOT in nanocomposites that is the result of interactions between PEDOT and $\mathrm{ZnO}^{35}$. Photocatalysts PEDOT/ZnO (1-2) and PEDOT/ZnO (1-3) show degradation between 180 and $350{ }^{\circ} \mathrm{C}$, and the whole PEDOT is degraded in two steps. On the other hand, thermal degradation of PEDOT/ $\mathrm{ZnO}(1-5)$ is seen in four steps and is completed at $566{ }^{\circ} \mathrm{C}$. From the obtained results, clearly seen is the effect of APS oxidant concentration, because in PEDOT/ZnO (1-2) nanocomposite, only 3 mass $\%$ of polymer is formed since the whole weight loss can be attributed to the organic polymer phase. The fraction of polymer significantly increases with APS concentration $(1-3,1-5)$ to 18 mass $\%$ and 51 mass $\%$, respectively as seen from the TG curves shown in Fig. 4. It can be concluded from the TG curves that the monomer/oxidant ratio has significant influence on the polymer structure that is reflected in the polymer properties. Higher ratio contributes to significantly higher conversion of monomer in the PEDOT/ZnO nanocomposites.

\section{UV-visible spectroscopy}

$\mathrm{UV}$-vis diffuse reflectance spectra of $\mathrm{ZnO}$, three PEDOT, and three PEDOT/ZnO samples are shown in Fig. 5. As may be seen from Fig. 5, $\mathrm{ZnO}$ 


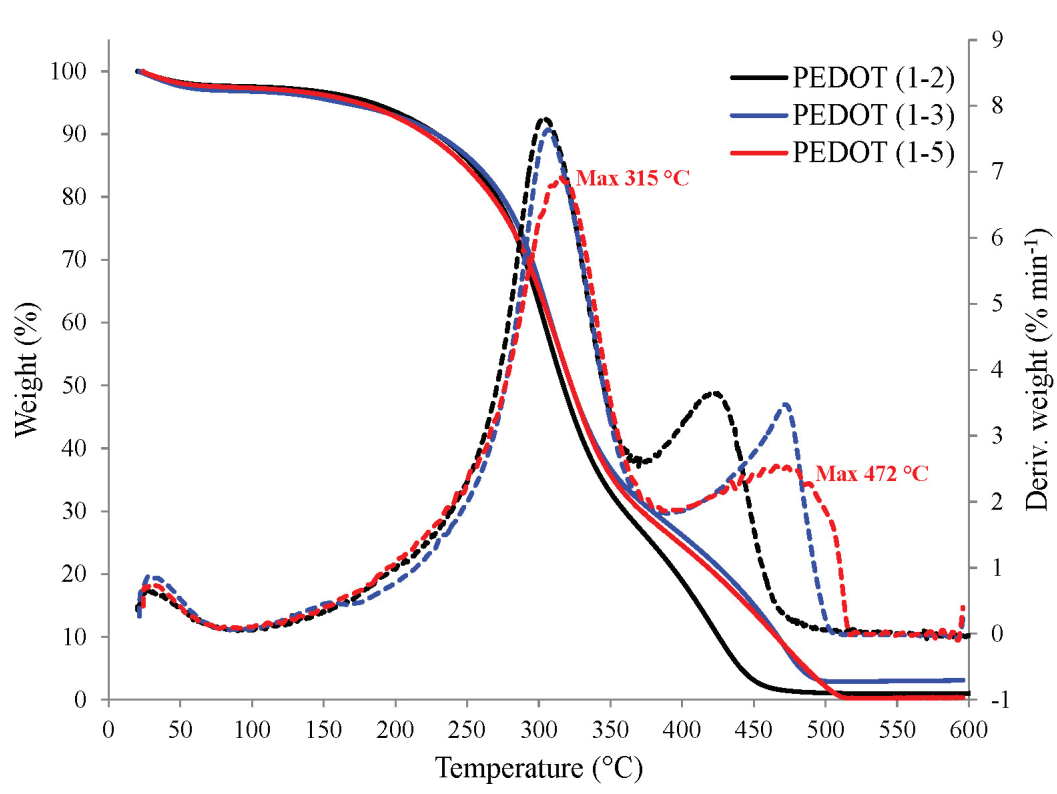

F ig. 3 - TG curves of PEDOT samples synthesized by various monomer to APS oxidant ratio $(1: 2,1: 3,1: 5)$

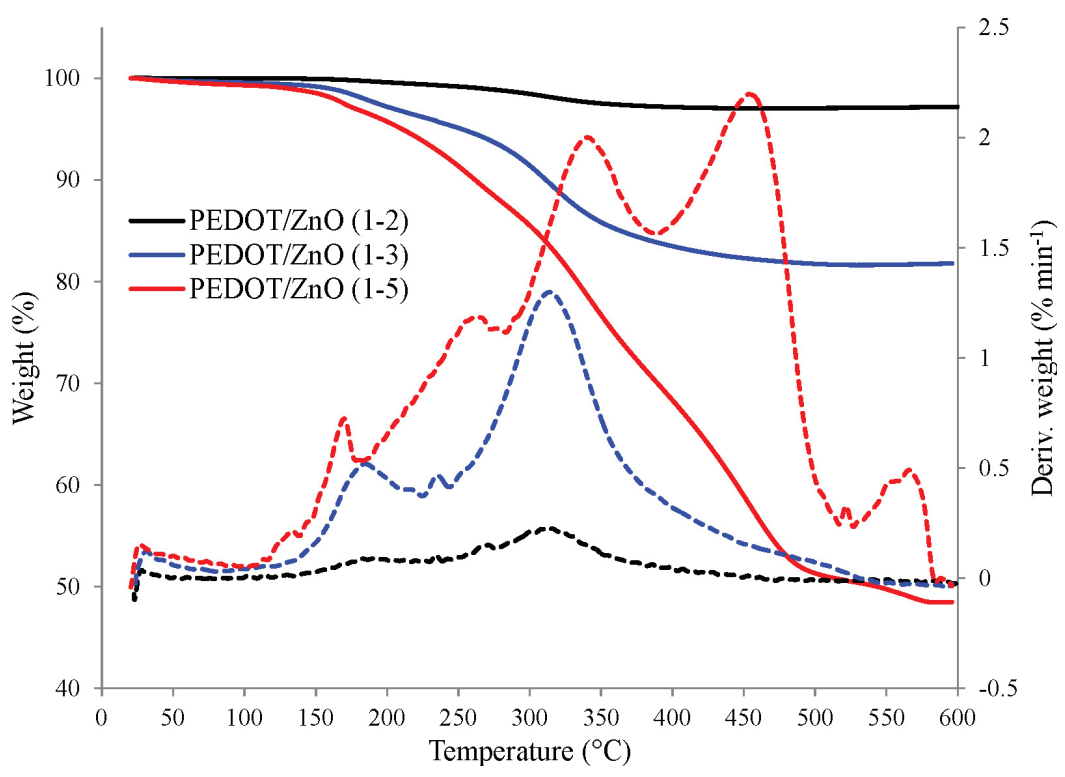

Fig. 4 - TG curves of PEDOT/ZnO samples synthesized by various monomer to APS oxidant ratio $(1: 2,1: 3,1: 5)$

absorbs light only in the UV region up to $390 \mathrm{~nm}$. Because of its wide band gap, there is no absorption of visible light, which is the main reason of poor degradation of organic molecules under visible light. On the other hand, PEDOT shows strong absorption in the range from UV to visible light. Composite photocatalysts have the characteristics of both $\mathrm{ZnO}$ and PEDOT, and they exhibit enhanced absorption over the entire UV-vis spectrum. It may be seen that the composite PEDOT/ZnO (1-5), which has the highest amount of the polymer, showed the highest absorption. Hence, it may function as an effective sensitizer to $\mathrm{ZnO}$ photocatalyst.
Photocatalytic mechanism is described in literature $^{36,37}$. The electrons in $\pi$-orbital of PEDOT are excited to $\pi^{*}$-orbital by visible light irradiation and can be injected into the conducting band of $\mathrm{ZnO}$ because their energy level is matched for the charge transfer. That way, the charge separation is enhanced, and electrons in conducting band of $\mathrm{ZnO}$ will react with water and oxygen to produce reactive oxidative species, which initiate reactions of photodegradation.

\section{SEM analysis}

To investigate the difference in morphologies of pure synthesized PEDOT polymers and PEDOT/ZnO nanocomposite photocatalysts, SEM micrographs were analyzed and are given in Fig. 6. Morphology of pure PEDOT polymers differ among themselves as it is observed that polymers form the aggregated particles. The size of primary particles seems to be larger for PEDOT (1-5) (Fig. 6c) than that of the other two samples PEDOT (1-2) (Fig. 6a) and PEDOT (1-3) (Fig. $6 a)$, and the morphology of polymer aggregates also differ in size and density. Thus, PEDOT (1-2) polymer shows the most friable (flaky) morphology, while the other two samples show a more condensed morphology as concentration of APS oxidant increases. One of the reasons are interactions established between the polymer chains as there are more suitable places on the chain for interactions, which leads to more dense morphology. It is assumed that in this way, the polymer charge form is reduced resulting in lower conductivity and photoactivity.

The similar observation can be made for PEDOT/ZnO nanocomposite photocatalysts (Fig. 6d,e,f). The PEDOT/ZnO (1-2) (Fig. 6d) sample has the loosest morphology structure. It could be seen that primary particles of $\mathrm{ZnO}$ form aggregates that later form porous morphology. The assumption that $\mathrm{ZnO}$ particles are dominant in morphology is supported by the result of TG analysis, which proved that only 3 mass \% of PEDOT polymer is present in nanocomposite. On the other hand, SEM images of PEDOT/ $\mathrm{ZnO}$ (1-3 and 1-5) nanocomposites show more dense morphology, which suggests that a significantly higher concentration of PEDOT polymer contributed to establishing strong interactions. It is assumed that polymer particles are on the surface of the zinc oxide particles, which is why they may 
have an effect on the type of the morphology. For the PEDOT/ZnO (1-5) sample, spherical PEDOT particles are clearly visible on the surface (Fig. 6f). Since the PEDOT polymer in PEDOT/ZnO (1-2) sample is present in very low concentrations, it is concluded that the polymer is distributed more like a thin layer over $\mathrm{ZnO}$ nanoparticles in the composite.

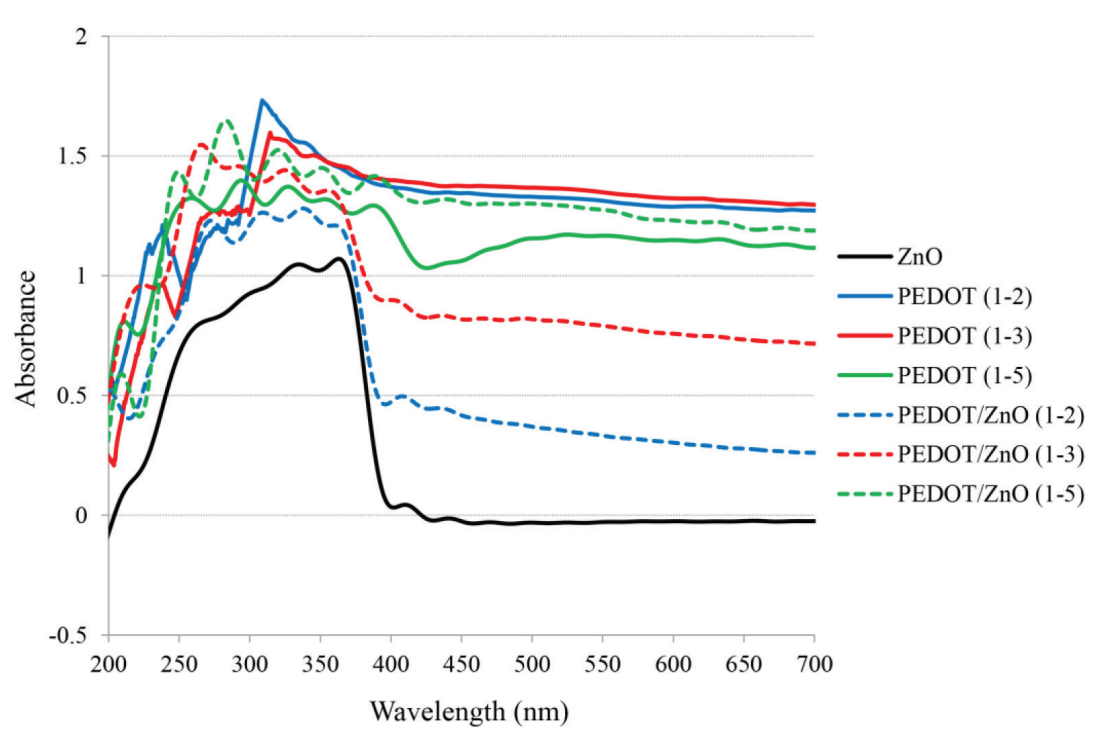

Fig. 5 - UV-Vis reflectance spectra of pure $\mathrm{ZnO}$ and synthesized PEDOT and PEDOT/ZnO samples
In literature ${ }^{38}$ it is reported that the grain size and connectivity control the conductivity of granular conductors. Thus, it is assumed that a thin layer of PEDOT polymer over $\mathrm{ZnO}$ nanoparticle increased the conductivity of PEDOT/ZnO (1-2) sample, while the aggregates of PEDOT polymers, due to high concentrations in other two nanocomposites, reduced it.

\section{XRD analysis}

To identify and clarify the structure of synthesized PEDOT polymers, XRD analysis was performed. In Fig. 7, the XRD diffraction patterns of pure PEDOT polymers synthesized with various concentrations of APS oxidant are seen. In all samples, exactly the same peaks are detected, at $2 \Theta=11^{\circ}$ and $36.5^{\circ}$ and one broad and high peak at $25^{\circ}$. A small additional peak at $17.5^{\circ}$ is observed for PEDOT (1-2) sample. A slight reduction in the intensity of all peaks with increasing concentrations of oxidants is noticed from which it can be concluded that a higher concentration of oxidants favors the formation of more amorphous structure. In Fig. 8, XRD diffraction patterns of PEDOT/ZnO

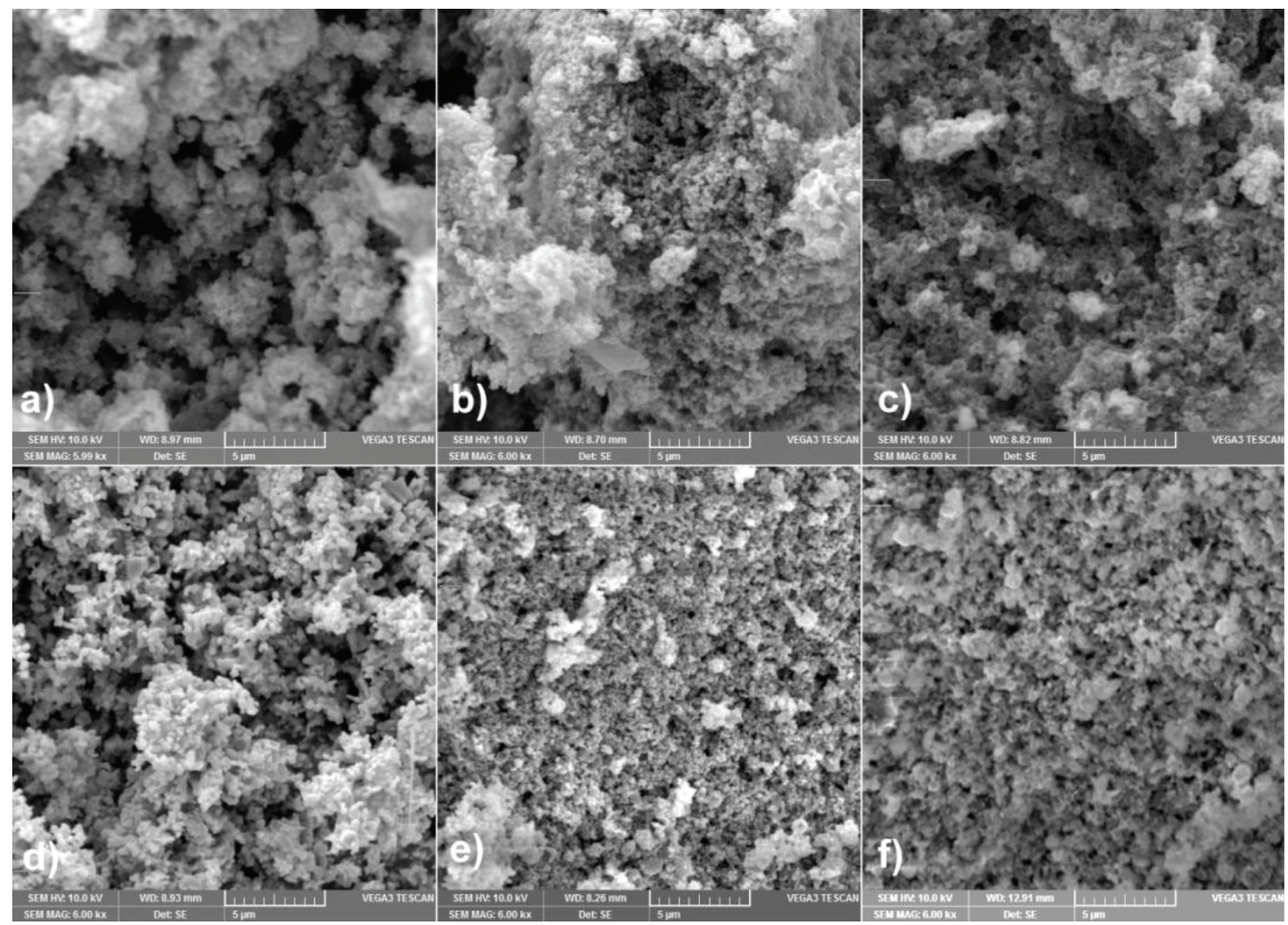

Fig. 6 - SEM micrographs a) PEDOT (1-2), b) PEDOT (1-3), c) PEDOT (1-5), d) PEDOT/ZnO (1-2), e) PEDOT/ZnO (1-3), f) PEDOT/ZnO (1-5) 


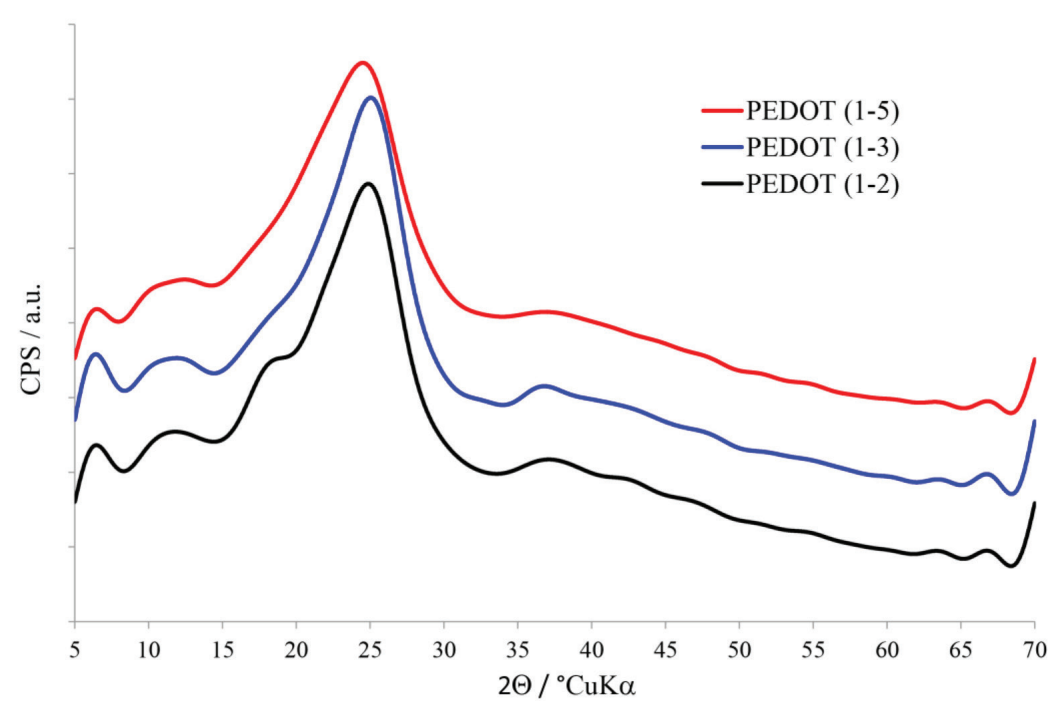

Fig. 7 - XRD diffractograms of PEDOT/ZnO samples synthesized at various monomer to APS oxidant ratio $(1: 2,1: 3,1: 5)$

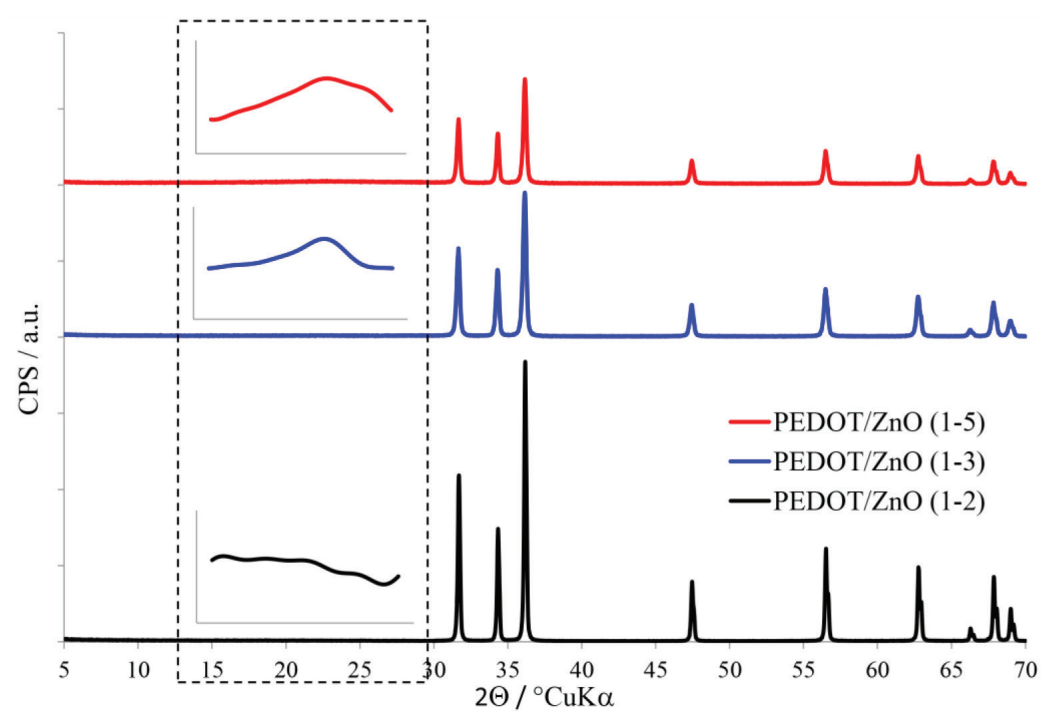

Fig. 8-XRD diffractograms of PEDOT/ZnO samples synthesized at various monomer to APS oxidant ratio $(1: 2,1: 3,1: 5)$

nanocomposite photocatalysts are presented where very intense peaks are visible with the maximums at $2 \Theta=31.7^{\circ}, 34.3^{\circ}, 36.2^{\circ}, 47.4^{\circ}, 56.5^{\circ}, 62.8^{\circ}$, $67.8^{\circ}$ and $69.0^{\circ}$ (JCPDS Data Card No: 36-1451) (39 $^{39}$. These peaks characterize the hexagonal $\mathrm{ZnO}$ wurtzite structure and as their intensity is about 30 times higher than the intensity of PEDOT polymer, the peaks of polymer are not visible. However, it is noticeable that the peak intensity of $\mathrm{ZnO}$ decreases with the increase in polymer concentration in nanocomposites which is very evident when comparing PEDOT/ZnO (1-2) and (1-5) samples. Further, a mild peak at $25^{\circ}$ can be discerned (Fig. 8, inset) which is characteristic of pure PEDOT and confirms its amorphous nature ${ }^{40}$. That peak appears for samples with higher concentration of polymer in composite, $\mathrm{PEDOT} / \mathrm{ZnO}(1-3)$ and $(1-5)$. The XRD results show that the increase in the polymer ratio in composite significantly affects the surface of $\mathrm{ZnO}$ photocatalyst.

\section{Photocatalytic activity}

The efficiency of the synthesized PEDOT/ZnO nanocomposite photocatalysts was examined by following the discoloration of RR45 dye in wastewater during photocatalysis under UV-A (Fig. 9) and simulated solar irradiation (Fig. 10). Due to high band gap of 3.2 $\mathrm{eV}, \mathrm{ZnO}$ is the photocatalyst that can be efficient in the process only under UV-A irradiation and PEDOT polymer can be photoactive in Vis part of the spectra (at $\lambda=610 \mathrm{~nm}$ ). Therefore, the experiments were carried out under both irradiations. Before starting the photocatalysis, it was necessary to achieve adsorption/desorption equilibrium, and therefore the suspension was stirred in the dark for half an hour. In that period, adsorption of RR45 onto the surface of catalyst takes place due to established interactions between the dye molecules and the catalyst. The highest degree of adsorption was observed onto PEDOT/ZnO (1-2) nanocomposite, and during that process $37 \%$ of the dye was removed, as may be seen in Fig. 9. It is well known that certain interactions need to be present during photocatalysis because the degradation of the contaminant (RR45) occurs at the surface of catalyst ${ }^{41}$. Too high adsorption of contaminant onto catalyst surface can slow down or even postpone the photodegradation, and thus reduce the efficiency of the catalyst itself ${ }^{42}$. This effect is well seen in both Figs. 9 and 10 at the beginning of the photocatalysis because some desorption of RR45 dye is observed as an increase in dye concentration in water. The photocatalysis under UV-A light (Fig. 9) proceeded for 90 minutes, where the initial concentration of RR45 was $30 \mathrm{mg} \mathrm{L}^{-1}$ and the concentration of the catalysts was $1 \mathrm{~g} \mathrm{~L}^{-1}$. The highest rate of RR45 dye degradation was achieved with PEDOT/ZnO (1-2) nanocomposite catalyst, as after 90 minutes only $25 \%$ of the dye remained in the wastewater, as visible in Fig. 9. The photocatalytic efficiency of the other nanocomposite photocatalysts (PEDOT/ZnO $(1-3,1-5)$ was significantly lower because $82 \%$ and $91 \%$ of RR45 dye, respectively, remained in the water. The results 
obtained for PEDOT/ZnO (1-2) composite photocatalysts can be considered as satisfying.

Photocatalysis under solar simulated irradiation was performed under the same conditions as mentioned above, and the results are given in Fig. 10 . It may be seen that the rate of photocatalytic degradation of RR45 dye was significantly lower for the studied nanocatalysts due to lower activation energy of solar irradiation that consisted of only $\sim 5 \%$ of UV-A light. However, good efficiency of photocatalytic activity of PEDOT/ZnO (1-2) nanocomposite catalyst is observed, because at the end of the process, $53 \%$ of RR45 remained in the water after 90 minutes. During the photocatalysis using PEDOT/ZnO (1-2), the rate of RR45 dye was completely satisfying, as every 15 minutes $10 \%$ of discoloration was noted. Here it should be pointed out that it was expected that PEDOT polymer would establish a synergic effect with $\mathrm{ZnO}$ catalysts in nanocomposite and improve the photocatalysis process under solar light. This can be confirmed only for the PEDOT/ZnO (1-2) sample, while for the other two nanocatalyst samples, the results indicate the absence of any synergic effect. On the contrary, higher concentration of PEDOT polymer in nanocomposite (1-3 and 1-5) exhibits congestion of $\mathrm{ZnO}$ catalyst. That significantly reflects on their photocatalytic activity as the photodegradation process had slowed down or completely stopped (sample 1-5). This behavior is also observed in the initial step of photocatalysis (first 15 minutes) of PEDOT/ZnO (1-2) catalysts by postponement of the process due to high concentration of adsorbed RR45 dye. Further, the results obtained by validation of photocatalytic activity under solar irradiation show that only PEDOT/ZnO (1-2) nanocatalyst indicates good conductivity and satisfying structure of PEDOT conductive polymer obtained during the synthesis.

\section{Conclusions}

The various chemical structures of synthesized PEDOT conductive polymer in pure polymer samples as well as in PEDOT/ZnO nanocomposite sam-

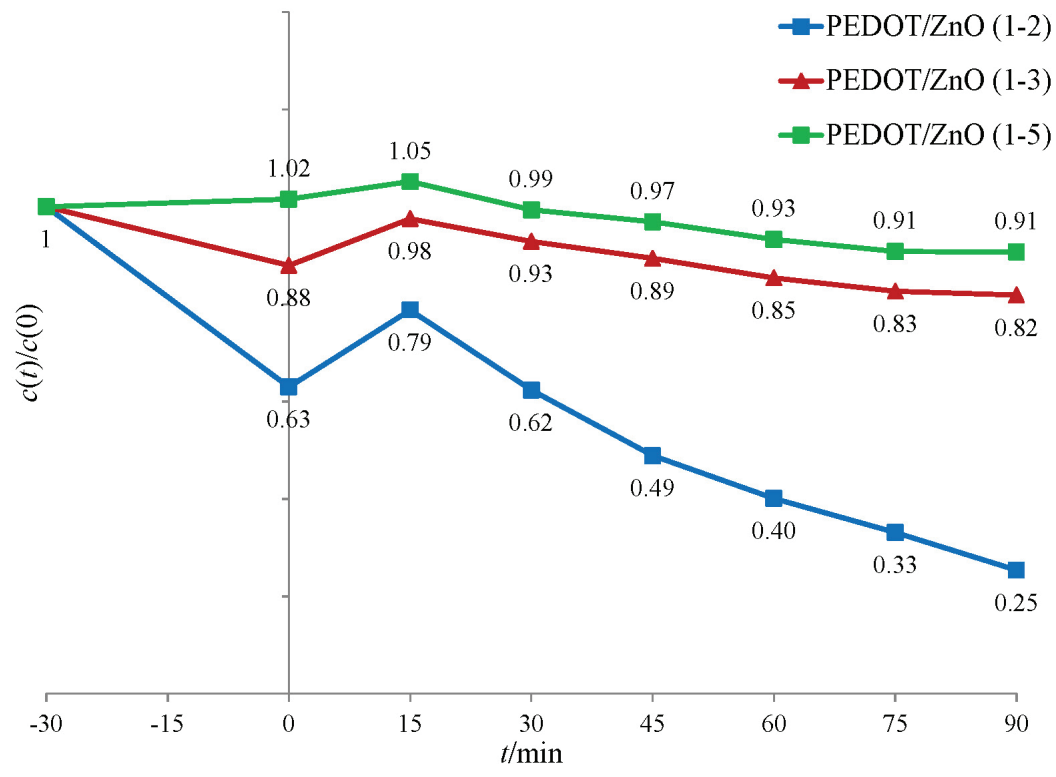

Fig. 9 - Rate of discoloration of RR45 dyes during photocatalysis under UV-A irradiation by using synthesized PEDOT/ZnO nanocomposite photocatalysts $\left(\gamma_{R R 45}=30 \mathrm{mg} \mathrm{L}^{-1}, \gamma_{\text {cat }}=1 \mathrm{~g} \mathrm{~L}^{-1}\right)$

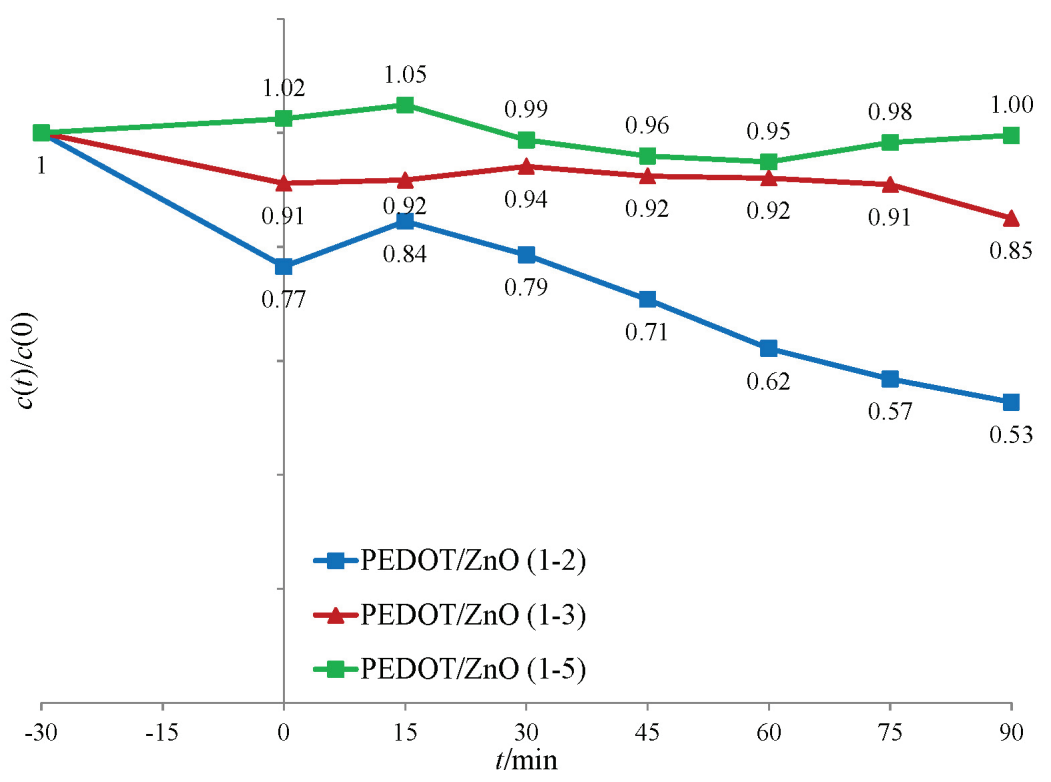

Fig. 10 - Rate of discoloration of RR45 dyes during photocatalysis under simulated solar irradiation by using synthesized composite PEDOT/ZnO nanocomposite photocatalysts $\left(\gamma_{R R 45}=30 \mathrm{mg} \mathrm{L}^{-1}, \gamma_{\text {cat }}=1 \mathrm{~g} \mathrm{~L}^{-1}\right)$

ples was established by FTIR spectroscopy, TG analysis, SEM microscopy and UV-vis spectroscopy as a result of changed concentration of APS oxidant. The conditions of synthesis were the same for the pure polymers and the PEDOT/ZnO nanocomposites, and it was found that a different structure of PEDOT conductive polymer is obtained. By FTIR spectrophotometry, altered charged forms were confirmed as n-doped in nanocomposite and $\mathrm{p}$ - and n-doped in pure polymer. By TG analysis, it was revealed that significantly different chemical struc- 
tures were obtained regarding the pure polymers and polymer in PEDOT/ZnO nanocomposites because of the different number of steps of thermal degradation, as seen from maximum degradation temperatures. It was also established that concentration increase of APS oxidant significantly affects the conversion of monomer, as for example, for PE$\mathrm{DOT} / \mathrm{ZnO}(1-2)$ nanocomposite only 3 mass $\%$ of polymer was present in nanocomposite. From the inspection of morphology, it was concluded that in $\mathrm{PEDOT} / \mathrm{ZnO}(1-2)$ nanocomposite only a thin layer of polymer over $\mathrm{ZnO}$ nanoparticles was formed, which is also seen from the XRD results. Higher concentration of PEDOT polymer in nanocomposite significantly lowers the intensity of $\mathrm{ZnO}$ maximums in XRD spectra by covering its surface. Finally, the validation of photocatalytic activity of PEDOT/ZnO nanocomposite catalysts by degradation of RR45 azo dye under UV-A light revealed very good efficiency of PEDOT/ZnO (1-2) catalyst. The rate of photocatalysis under solar light was significantly lower although PEDOT/ZnO (1-2) catalyst showed the highest efficiency. From the results, it is concluded that a very low concentration of PEDOT conductive polymer in PEDOT/ZnO nanocomposite photocatalysts has to be present, otherwise it covers $\mathrm{ZnO}$ nanoparticle surface completely and slows down the photocatalysis significantly.

\section{ACKNOWLEDGEMENT}

This work has been fully supported by Croatian Science Foundation under the project HRZZ-5092.

\section{References}

1. Jain, R., Gupta, V. K., Sikarwar, S., Adsorption and desorption studies on hazardous dye Naphthol Yellow S, J. Hazard. Mater. 182 (2010) 749.

doi: https://doi.org/10.1016/j.jhazmat.2010.06.098

2. Platzek, T., Lang, C., Grohmann, G., Gi, U. S., Baltes, W., Formation of a carcinogenic aromatic amine from an azo dye by human skin bacteria in vitro, Hum. Exp. Toxicol. 18 (1999) 552.

doi: https://doi.org/10.1191/096032799678845061

3. Arab Chamjangali, M., Bagherian, G., Bahramian, B., Fahimi Rad, B., Synthesis and application of multiple rods gold-zinc oxide nanostructures in the photocatalytic degradation of methyl orange, Int. J. Environ. Sci. Technol. 12 (2015) 151

doi: https://doi.org/10.1007/s13762-014-0669-x

4. Wang, Y., Bai, X., Pan, C., He, J., Zhu, Y., Enhancement of photocatalytic activity of $\mathrm{Bi}_{2} \mathrm{WO}_{6}$ hybridized with graphite-like $\mathrm{C}_{3} \mathrm{~N}_{4}$, J. Mater. Chem. 22 (2012) 11568. doi: https://doi.org/10.1039/c2jm16873a

5. Dong, W., Lee, C. W., Lu, X., Sun, Y., Hua, W., Zhuang, G., Zhang, S., Chen, J., Hou, H., Zhao, D., Synchronous role of coupled adsorption and photocatalytic oxidation on ordered mesoporous anatase $\mathrm{TiO}_{2}-\mathrm{SiO}_{2}$ nanocomposites generating excellent degradation activity of RhB dye, Appl. Catal. B 95 (2010) 197.

doi: https://doi.org/10.1016/j.apcatb.2009.12.025
6. Deng, F., Min, L., Luo, X., Wu, S., Luo, S., Visible-light photocatalytic degradation performances and thermal stability due to the synergetic effect of $\mathrm{TiO}_{2}$ with conductive copolymers of polyaniline and polypyrrole, Nanoscale $\mathbf{5}$ (2013) 8703. doi: https://doi.org/10.1039/c3nr02502k

7. Hazrati, N., Abdouss, M., Vahid, A., Removal of $\mathrm{H}_{2} \mathrm{~S}$ from crude oil via stripping followed by adsorption using $\mathrm{ZnO} /$ MCM-41 and optimization of parameters, Int. J. Environ. Sci. Technol. 11 (2014) 997.

doi: https://doi.org/10.1007/s13762-013-0465-z

8. Daneshvara, N., Salarib, D., Khataee, A. R., Photocatalytic degradation of azo dye acid red 14 in water on $\mathrm{ZnO}$ as an alternative catalyst to $\mathrm{TiO}_{2}$, J. Photochem. Photobiol. A 162 (2004) 317. doi: https://doi.org/10.1016/S1010-6030(03)00378-2

9. Li, H., Bian, Z., Zhu, J., Huo, Y., Li, H., Lu, Y., Mesoporous $\mathrm{Au} / \mathrm{TiO}_{2}$ nanocomposites with enhanced photocatalytic activity, J. Phys. Chem. C 129 (2007) 4538.

10. Yu, J., Xiang, Q., Zhou, M., Preparation, characterization and visible-light-driven photocatalytic activity of Fe-doped titania nanorods and first-principles study for electronic structures, Appl. Catal. B 90 (2009) 595. doi: https://doi.org/10.1016/j.apcatb.2009.04.021

11. Ghasemi, S., Rahimnejad, S., Rahman Setayesh, S., Rohani, S., Gholami, M. R., Transition metal ions effect on the properties and photocatalytic activity of nanocrystalline $\mathrm{TiO}_{2}$ prepared in an ionic liquid, J. Hazard. Mater. 172 (2009) 1573 doi: https://doi.org/10.1016/j.jhazmat.2009.08.029

12. Dong, F., Wang, H., Wu, Z., One-step "green" synthetic approach for mesoporous c-doped titanium dioxide with efficient visible light photocatalytic activity, J. Phys. Chem. C 113 (2009) 16717. doi: https://doi.org/10.1021/jp9049654

13. Liu, G., Chen, Z., Dong, C., Zhao, Y., Li, F., Lu, G. Q., Cheng, H.-M., Visible light photocatalyst: Iodine-doped mesoporous titania with a bicrystalline framework, J. Phys. Chem. B 110 (2006) 20823.

14. Kuo, Y.-L., Su, T.-L., Kung, F.-C., Wu, T.-J., A study of parameter setting and characterization of visible-light driven nitrogen-modified commercial $\mathrm{TiO}_{2}$ photocatalysts, J. Hazard. Mater. 190 (2011) 938. doi: https://doi.org/10.1016/j.jhazmat.2011.04.031

15. Wang, X., Blackford, M., Prince, K., Caruso, R. A., Preparation of boron-doped porous titania networks containing gold nanoparticles with enhanced visible-light photocatalytic activity, Appl. Mater. Interfaces. 4 (2012) 476. doi: https://doi.org/10.1021/am201695c

16. Choi, S. K., Kim, S., Lim, S. K., Park, H., Photocatalytic comparison of $\mathrm{TiO}_{2}$ nanoparticles and electrospun $\mathrm{TiO}_{2}$ nanofibers: Effects of mesoporosity and interparticle charge transfer, J. Phys. Chem. C 114 (2010) 16475.

17. Zhang, J., Li, L., Yan, T., Li, G., Selective Pt deposition onto the face (110) of $\mathrm{TiO}_{2}$ assembled microspheres that substantially enhances the photocatalytic properties, J. Phys. Chem. C 115 (2011) 13820. doi: https://doi.org/10.1021/jp203511z

18. Eren, E., Celik, G., Uygun, A., Tabaciarova, J., Omastova, $M$., Synthesis of poly(3,4-ethylenedioxythiophene)/titanium dioxide nanocomposites in the presence of surfactants and their properties, Synthetic Met. 162 (2012) 1451. doi: https://doi.org/10.1016/j.synthmet.2012.06.014

19. Karim, M. R., Lim, K. T., Lee, C. J., Bhuivan, M. T. I., Kim, H. J., Park, L.-S., Lee, M. S., Synthesis of core-shell silverpolyaniline nanocomposites by gamma radiolysis method, J. Polym. Sci. A Polym. Chem. 45 (2007) 5741. doi: https://doi.org/10.1002/pola.22323 
20. Karim, M. R., Lee, H. W., Cheong, I. W., Park, S. M., Oh, $W$., Yeum, J. H., Conducting polyaniline-titanium dioxide nanocomposites prepared by inverted emulsion polymerization, Polym. Compos. 31 (2010) 83.

21. Nuraje, N., Su, K., Yang, N.-I., Matsui, H., Liquid/liquid interfacial polymerization to grow single crystalline nanoneedles of various conducting polymers, ACS Nano 2 (2008) 502. doi: https://doi.org/10.1021/nn7001536

22. Hong, S.-Y., Park, S.-M., Electrochemistry of conductive polymers 36 . $\mathrm{pH}$ dependence of polyaniline conductivities studied by current-sensing atomic force microscopy, J. Phys. Chem. B 109 (2005) 9305. doi: https://doi.org/10.1021/jp050173g

23. Muktha, B., Mahanta, D., Patil, S., Madras, G., Synthesis and photocatalytic activity of poly(3-hexylthiophene)/ $/ \mathrm{TiO}_{2}$ composites, J. Solid State Chem. 180 (2007) 2986. doi: https://doi.org/10.1016/j.jssc.2007.07.017

24. Goubard, F., Aubert, P.-H., Boukerma, K., Pauthe, E., Chevrot, $C$., Elaboration of nanohybrid materials by photopolymerisation of 3,4-ethylenedioxythiophene on $\mathrm{TiO}_{2}$, Chem. Commun. 27 (2008) 3139. doi: https://doi.org/10.1039/b800754c

25. Groenendaal, L. B., Jonas, F., Freitag, D., Pielartzik, H., Reynolds, J. R., Poly(3,4-ethylenedioxythiophene) and its derivatives: past, present, and future, Adv. Mater. 12 (2000) 481.

26. Kumar, A., Reynolds, J. R., Soluble alkyl-substituted poly(ethylenedioxythiophenes) as electrochromic materials, Macromolecules 29 (1996) 7629. doi: https://doi.org/10.1021/ma960879w

27. Dietrich, M., Heinze, J., Heywang, G., Jonas, F., Electrochemical and spectroscopic characterization of polyalkylenedioxythiophenes, J. Electroanal. Chem. 369 (1994) 87. doi: https://doi.org/10.1016/0022-0728(94)87085-3

28. Gustafsson, J. C., Liedberg, B., Inganas, O., In situ spectroscopic investigations of electrochromism and ion transport in a poly (3,4-ethylenedioxythiophene) electrode in a solid state electrochemical cell, Solid State Ionics 69 (1994) 145. doi: https://doi.org/10.1016/0167-2738(94)90403-0

29. Kvarnström, C., Neugebauer, H., Blomquist, S., Ahonen, $H$. J., Kankare, J., Ivaska, A., In situ spectroelectrochemical characterization of poly(3,4-ethylenedioxythiophene), Electrochim. Acta 44 (1999) 2739.

doi: https://doi.org/10.1016/S0013-4686(98)00405-8

30. Hernandez, V., Ramirez, F. J., Otero, T. F., Lopez Navarrete, $J$. T., An interpretation of the vibrational spectra of insulating and electrically conducting poly(3-methylthiophene) aided by a theoretical dynamical model, J. Chem. Phys. 100 (1994) 114. doi: https://doi.org/10.1063/1.466982

31. Kvarnström, C., Neugebauer, H., Ivaska, A., Sariciftci, N. $S$., Vibrational signatures of electrochemical p- and n-doping of poly(3,4-ethylenedioxythiophene) films: an in situ attenuated total reflection Fourier transform infrared (ATRFTIR) study, J. Mol. Struct. 521 (2000) 271.
32. Sowri Babu, K., Ramachandra Reddy, A., Sujatha, C., Venugopal Reddy, K., Mallika, A. N., Synthesis and optical characterization of porous $\mathrm{ZnO}$, J. Adv. Ceramic 2 (2013) 260.

doi: https://doi.org/10.1007/s40145-013-0069-6

33. Choi, J. W., Han, M. G., Kim, S. Y., Oh, S. G., Im, S. S., Poly(3,4-ethylenedioxythiophene) nanoparticles prepared in aqueous DBSA solutions, Synth. Met. 141 (2004) 293. doi: https://doi.org/10.1016/S0379-6779(03)00419-3

34. Kiebooms, R., Aleshin, A., Hutchison, K., Wudl, F., Heeger, $A$., Doped poly(3,4-ethylenedioxythiophene) films: thermal, electromagnetical and morphological analysis, Synthetic Met. 101 (1999) 436.

35. Sen, P., De, A., Chowdhury, A. D., Bandyopadhyay, S. K., Agnihotri, N., Mukherjee, M., Conducting polymer based manganese dioxide nanocomposite as supercapacitor, Electrochim. Acta 108 (2013) 265. doi: https://doi.org/10.1016/j.electacta.2013.07.013

36. Li, X., Wang, D., Cheng, G., Luo, Q., An, J., Wang, Y., Preparation of polyaniline-modified $\mathrm{TiO}_{2}$ nanoparticles and their photocatalytic activity under visible light illumination, Appl. Catal. B: Environ 81 (2008) 267.

37. Zhang, H., Zong, R., Zhao, J., Zhu, Y., Dramatic visible photocatalytic degradation performances due to synergetic effect of $\mathrm{TiO}_{2}$ with PANI, Environ. Sci. Technol. 42 (2008) 3803. doi: https://doi.org/10.1021/es703037x

38. Sen, $P$., De, A., Electrochemical performances of poly(3,4-ethylenedioxythiophene)- $\mathrm{NiFe}_{2} \mathrm{O}_{4}$ nanocomposite as electrode for supercapacitor, Electrochim. Acta 55 (2010) 4677. doi: https://doi.org/10.1016/j.electacta.2010.03.077

39. Sarma, H., Sarma, K. C., X-ray peak broadening analysis of $\mathrm{ZnO}$ nanoparticles derived by precipitation method, Int. J. Sci. Res. Pub. 4 (2014) 1.

40. Gupta, B., Mehta, M., Melvin, A., Kamalakannan, R., Dash, S., Kamruddin, M., Tyagi, A. K., Poly (3,4-ethylenedioxythiophene) (PEDOT) and poly(3,4-ethylenedioxythiophene)-few walled carbon nanotube (PEDOT-FWCNT) nanocomposite based thin films for Schottky diode application, Mater. Chem. Phys. 147 (2014) 867. doi: https://doi.org/10.1016/j.matchemphys.2014.06.032

41. Daneshvar, N., Salari, D., Khataee, A. R., Photocatalytic degradation of azo dye Acid Red 14 in water: investigation of the effect of operational parameters, J. Photochem. Photobiol. A 157 (2003) 111. doi: https://doi.org/10.1016/S1010-6030(03)00015-7

42. Kusvuran, E., Gulnaz, O., Irmak, S., Atanur, O. M., Yavuz, H. I., Erbatur, O., Comparison of several advanced oxidation processes for the decolorization of Reactive Red 120 azo dye in aqueous solution, J. Hazard. Mater. 109 (2004) 85 . doi: https://doi.org/10.1016/j.jhazmat.2004.03.009 